\title{
Evaluation of the Ingestive Behavior of Foreign Fragments and the Integrity of Gastrointestinal Tract of Broiler Chickens
}

\section{-Author(s)}

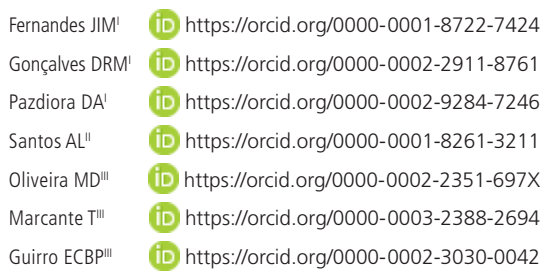

Laboratory of Poultry Experimentation, Department of Animal Science, Federal University of Paraná - Palotina, Palotina, PR, 85950-000, Brazil

Animal Science Department, Federal University of Paraná - Palotina, Palotina, PR, 85950-000, Brazil.

III Veterinary Science Department, Federal University of Paraná - Palotina, Palotina, PR, 85950-000, Brazil.

\section{ABSTRACT}

Fragments with vibrant colors and attractive textures in poultry house litter may be consumed considering that the confinement environment does not offer many opportunities for the development of the birds's natural behavior. Control and quality programs aiming to reduce and to eliminate the consumption of materials from the construction of sheds have been implanted. However, it is necessary to develop studies for a better understanding of the bird's ingestive behavior and the consequences for their health, welfare and productivity. The goal of this study was to evaluate the ingestive behavior of broilers exposed to metal, wood, glass and plastic fragments at different concentrations and sizes added to the poultry house litter and the integrity of the gastrointestinal tract of broilers. A total of 360 birds were distributed in a completely randomized design over a $2 \times 3$ factorial scheme (2 fragment sizes: 2 to $7 \mathrm{~mm}$ and 5 to $8 \mathrm{~mm}$ and 3 concentrations: $0.1,0.5$ and $1 \%)$, totaling 6 treatments and 5 replicates. The fragments used were glass, wood, metal and plastic, in respective concentrations and sizes, distributed in the poultry house litter. The supply of fragments or the accidental occurrence of similar fragments to which were analyzed in this study concerning the poultry house litter, with different sizes, colors and textures does not compromise the integrity of the mucosa of the gastrointestinal tract and the welfare of the birds.

\section{INTRODUCTION}

The fast development of Brazilian broiler industry has led Brazil to the ranking of the world's leading producers, mainly due to the favorable climatic conditions and comparative advantages found in the Brazilian territory (Waker \& Nääs, 2018). Factors such as quality, sanity and price have contributed to improving productivity in the industry. Brazil sought modernization using instruments such as adequate management of the aviary, sanitation, balanced feeding, genetic improvement, and integrated production. The partnership between industry and poultry farmers has also contributed to technical excellence at all stages of the production chain, resulting in reduced transaction costs and quality that meets the demands of the world (Nääs et al., 2015).

Along with this, there is an increasing concern of the consumers with food quality, from the decrease of health risk, the content and the benefits, presence of pesticide residues and other precursors of diseases, to the use of genetically modified raw materials and the operation and manipulation of the products (Pilleco et al., 2012). In addition, consumers began to get in touch with the subject of animal welfare through media, highlighting the improvement of product's quality from animal breeding, because the meat from well-treated animals from birth to slaughter will undoubtedly present better appearance, 
Fernandes JIM, Gonçalves DRM, Pazdiora DA, Santos AL, Oliveira MD, Marcante T, Guirro ECBP
Evaluation of the Ingestive Behavior of Foreign Fragments and the Integrity of Gastrointestinal Tract of Broiler Chickens texture and taste (Oliveira et al., 2008), resulting in a demand for animal welfare that grows in parallel with the socioeconomic development of broiler industry to fit the consumer's profile (Napolitano et al., 2010).

Focusing on animal welfare, birds should be raised under adequate protection and comfort. However, the ancestral behavior of pecking and scratching remains in confinement system adopted by the poultry industry (Joseph et al., 1992). Which may result in the consumption of fragments that are foreign to the diet and poultry house litter, compromising innate behavior causing pain, fear, and distress (Aruljothi et al., 2017). In addition, these fragments may further compromise the health status of broiler chickens and ultimately the health or the perspective of meat quality by the consumer (Napolitano et al., 2010; Benjamin et. al., 2015).

Nevertheless, there are no studies about the potential for consumption of common fragments within poultry facilities, such as metal, glass, plastic, and wood. Maintenance, repairs, and equipment exchanges can generate attractive fragments to the birds. In the poultry house litter used to prevent direct contact of the animals with the floor, to promote the absorption of water and to incorporate feces and feathers (Fiorentin, 2005; Bilgili, 2009), may be a vehicle to the consumption of foreign objects, since it consists of particles of many sizes. In addition, the mixture with the bird's excreta can camouflage these materials and, depending on the color and texture, it may be attractive and in consequence consumed by the birds, considering also that the confinement environment does not offer many opportunities for the development of the bird's natural behavior (Aruljothi et al., 2017).

On the other hand, the literature presents regulatory action criteria for foreign objects found in food for humans (Olsen, 1998; Olsen et al., 2001). These authors report that the severity of lesions in people who accidentally consume fragments contained in food is correlated with the size, the hard and sharp characteristics of these fragments. Hard or sharp fragments or objects of $7 \mathrm{~mm}$ or more were considered a potential health hazard due to laceration, perforation, and possible secondary infection. Objects smaller than $7 \mathrm{~mm}$ in size represent a potential danger, especially for children or elderly people. Besides the physical risk, objects and fragments may also constitute biological and chemical risks, depending on the composition and origin (Olsen et al., 2001).
The goal of this paper was to evaluate the ingestion behavior of broilers exposed to metal, wood, glass and plastic fragments at different concentrations and sizes added to the poultry house litter and the integrity of the gastrointestinal tract of the broilers.

\section{MATERIALS AND METHODS}

The experiment was performed in the Experimental Aviary of the University Federal do Paraná, Sector Palotina. All procedures for raising animals and collecting biological material were approved by the Committee for Ethical Conduct in the Use of Animals (CEUA), under the protocol number 23/2016.

360 one-day-old birds were distributed in a completely randomized design in a $2 \times 3$ factorial scheme (2 fragment sizes: 5 to $8 \mathrm{~mm}$ and 8 to $11 \mathrm{~mm}$ and 3 concentrations: $0.1,0.5$ and $1 \%$ ), totaling 6 treatments and 5 replicates.

The birds of all treatments had access to water and feed ad libitum, and were maintained on thermal comfort $\left(26-31^{\circ} \mathrm{C}\right)$. From days 1 to 6 , the birds received wood shavings poultry house litter free of fragments. On the 7th day the fragments were included in the poultry house litters on the concentration of $0.1 \%$, $0.5 \%$ and $1 \%$. The fragments of metal, plastic, wood and glass were cut in sizes from 5 to $8 \mathrm{~mm}$ and 8 to $11 \mathrm{~mm}$, measured with the aid of a caliper (Figures 1 and 2).

At 14 days, two birds from each experimental unit (10 birds per treatment) were slaughtered to evaluate the following conditions:

a) Laceration of the mouth, tongue or throat

b) Laceration and/or intestinal perforation

c) Presence of lesions or signs of secondary infection

The contents of the crop, proventriculus/gizzard and intestine were collected and washed in a sieve to identify the consumption of the fragments with the use of a magnifying glass. The fragments were identified, separated, counted and weighed. However, for the statistical analysis, the weight of the fragments was considered. The mucosal integrity of the esophagus, crop, proventriculus/gizzard and intestine was evaluated for the absence or presence of lesions using the lesion score, classified as mild, moderate or severe.

Data regarding the presence of fragments in the gastrointestinal tract were analyzed using the GENMOD procedure of SAS (SAS Institute, 2002). For the metal, plastic and wood fragments, the normal distribution with an identity link function was used. For 
Fernandes JIM, Gonçalves DRM,

Pazdiora DA, Santos AL, Oliveira MD,

Marcante T, Guirro ECBP

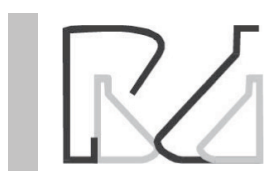

Evaluation of the Ingestive Behavior of Foreign Fragments and the Integrity of Gastrointestinal Tract of Broiler Chickens
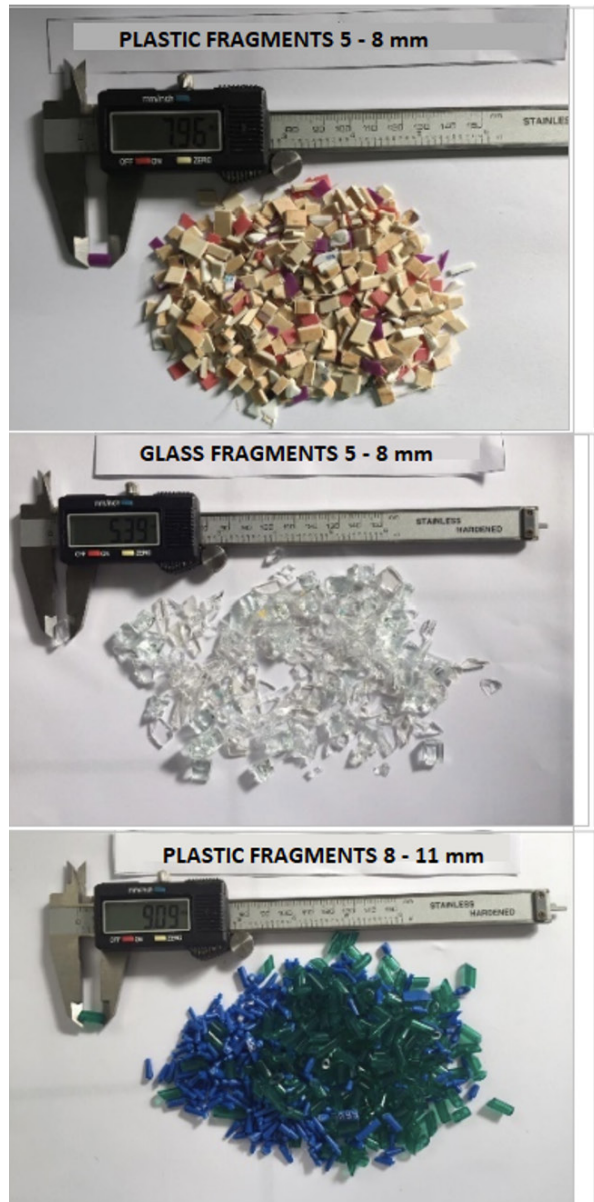
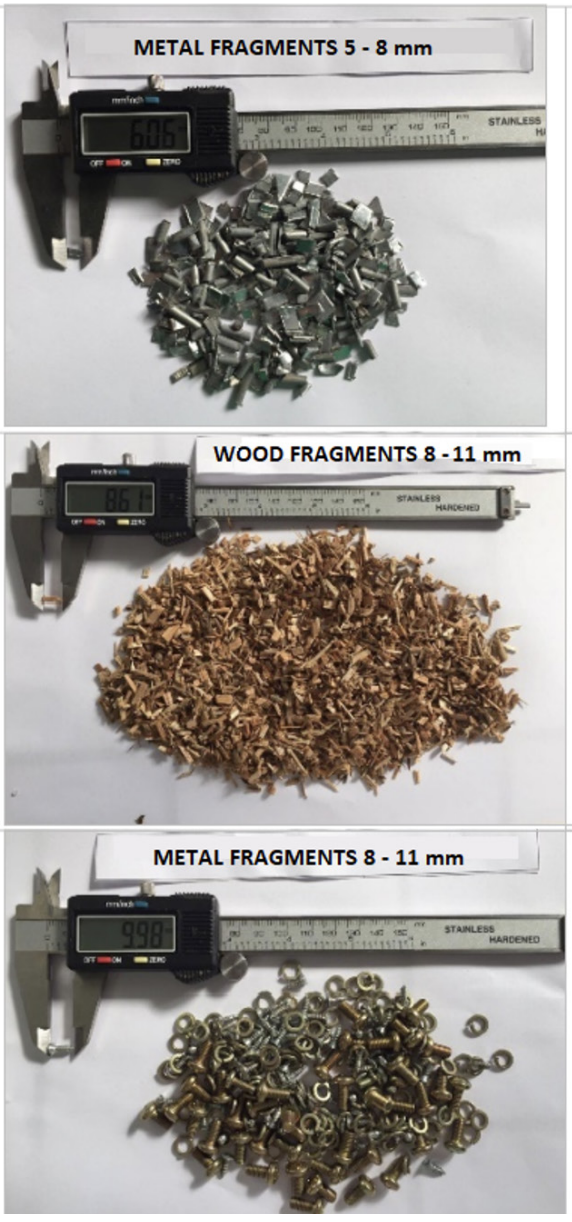
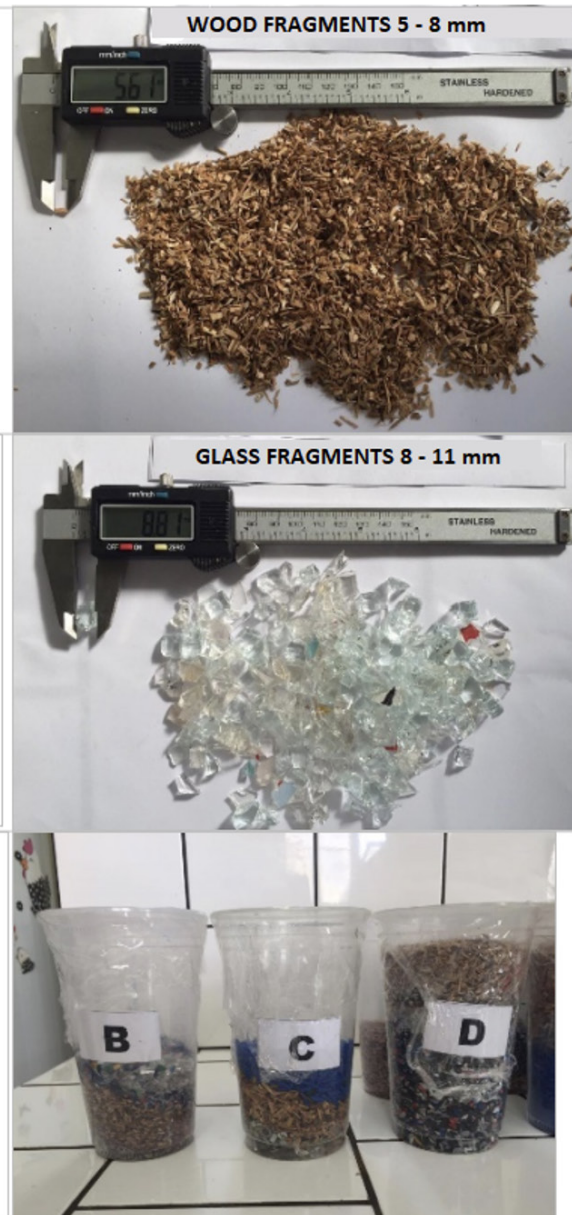

Figure 1 - Preparation of the fragments for inclusion in the poultry house litter.
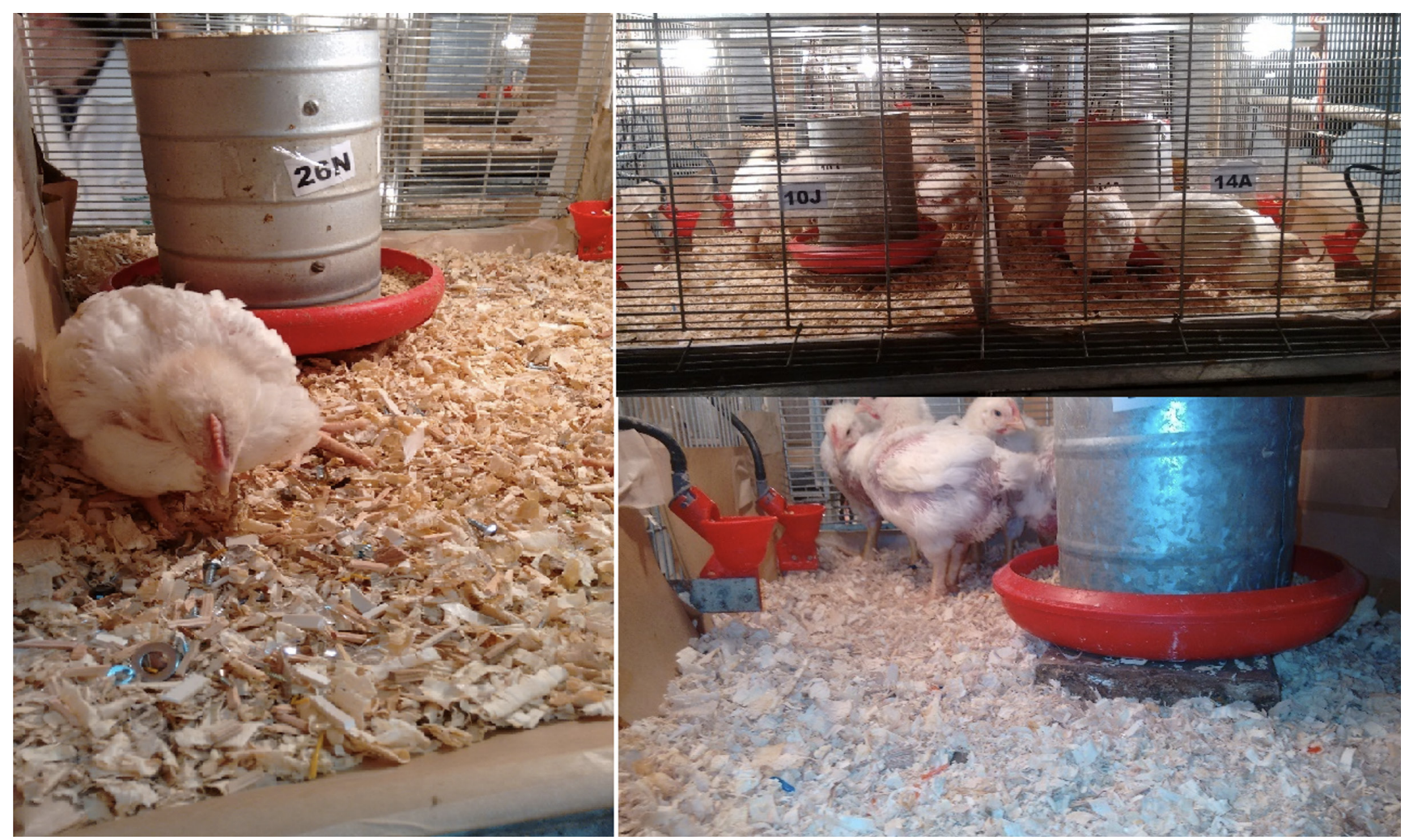

Figure $\mathbf{2}$ - Mixed fragments in the poultry house litter. 
Fernandes JIM, Gonçalves DRM, Pazdiora DA, Santos AL, Oliveira MD, Marcante T, Guirro ECBP

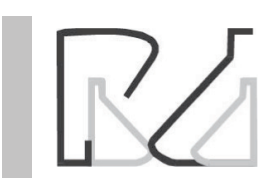

the data of the glass fragments, the negative binomial distribution and log link were chosen. The data relative to the lesion scores were analyzed by the chi-square test.

\section{RESULTS AND DISCUSSION}

The results regarding the presence of metal, plastic, wood, and glass fragments in the gastrointestinal tract of 14-day-old broilers (Figure 3 ) are shown in Table 1. Significant interaction $(p<0.05)$ has been observed for the weight of the metal particles. There was an opposite effect for fragment's size. Larger particles were more consumed $(p<0.05)$ as concentration of fragments in the poultry house litter increased, while smaller particles were less consumed $(p<0.05)$ when concentration increased.

The analysis of the fragments count revealed a significant interaction $(p<0.05)$ for all fragments. For the counting of metal, the same pattern observed on weight analysis of the metal fragments was reported. Regarding plastic fragments, there was a higher ingestion $(p<0.05)$ for smaller particles $(5-8 \mathrm{~mm})$ included in high concentrations $(1,0 \%)$, whereas wood fragments behaved inconsistently, with a higher count for intermediate concentrations $(0.5 \%)$. This occurred probably due to the similar nature of the wood shavings poultry house litter with the wood fragments. For glass
Evaluation of the Ingestive Behavior of Foreign Fragments and the Integrity of Gastrointestinal Tract of Broiler Chickens
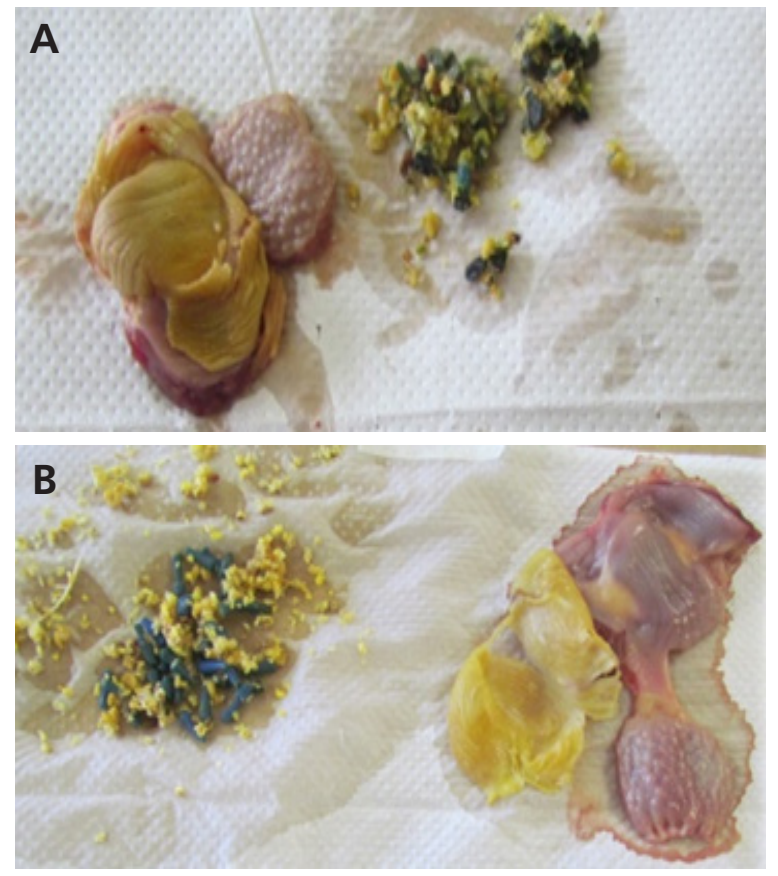

Figure 3 - Collection of digestive organs of 14-day-old broilers - poultry house litter fragments. A: fragments of 5 to $8 \mathrm{~mm}$. B: fragments from 8 to $11 \mathrm{~mm}$.

it was observed that smaller fragments $(5-8 \mathrm{~mm})$ and in lower concentration were more frequent in the count.

Table 2 show the results regarding the counting and weight of the fragments in the gastrointestinal tract of 21 -day-old broilers. No significant interaction ( $p>0.05$ ) was reported for the weight of fragments, except for glass, which had a higher consumption $(p<0.05)$ for

Table 1 - Analysis of weight (grams) and number of fragments found in the gastrointestinal tract of birds at 14 days of age, unfolding the interaction Size $x$ Concentration.

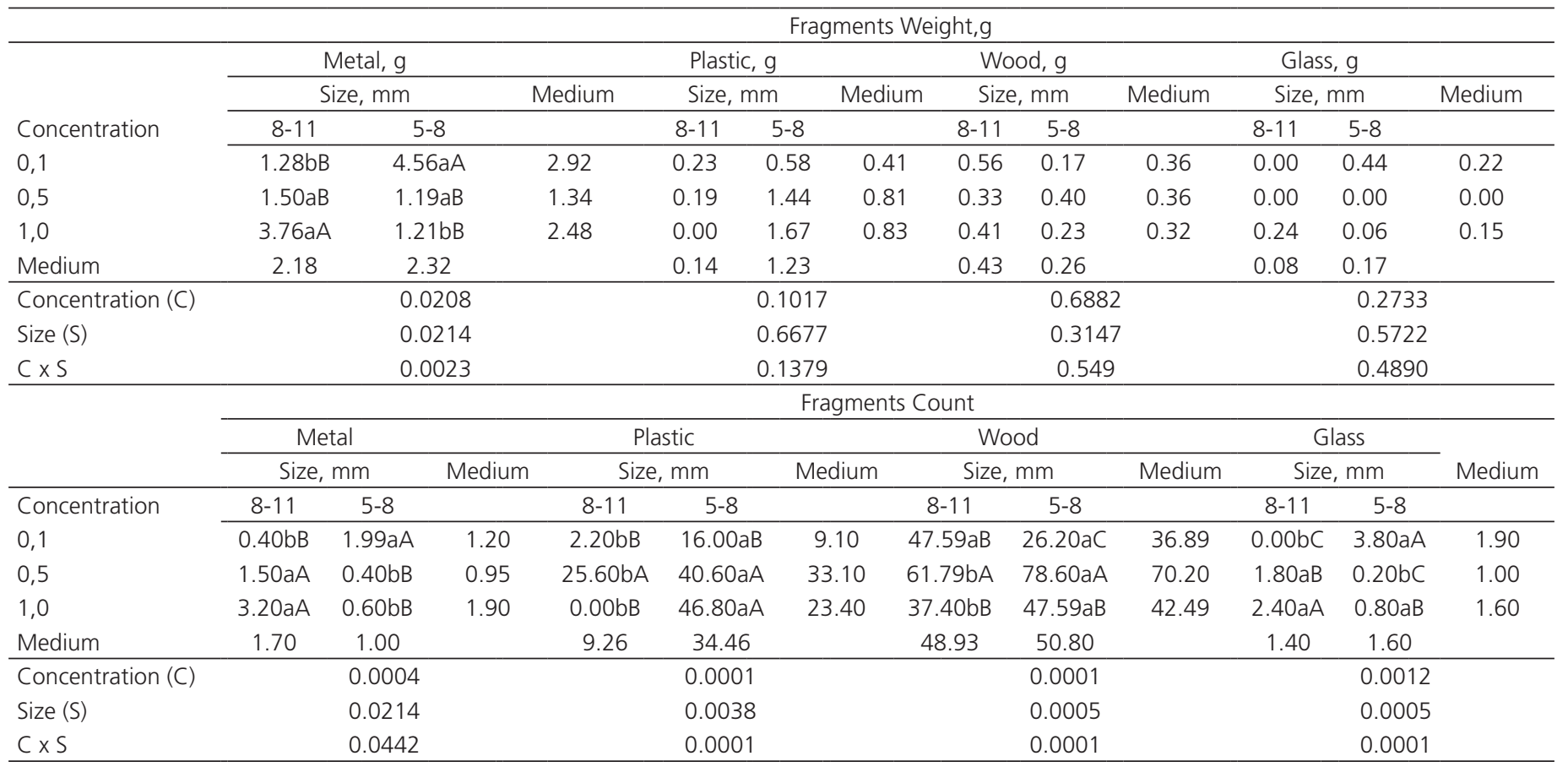

Lowercase letters in the column differ significantly and capital letters in the line differ significantly $(p<0.05)$. 
Table 2 - Analysis of weight (grams) and number of fragments found in the gastrointestinal tract of birds at 21 days of age, unfolding the interaction Size $x$ Concentration.

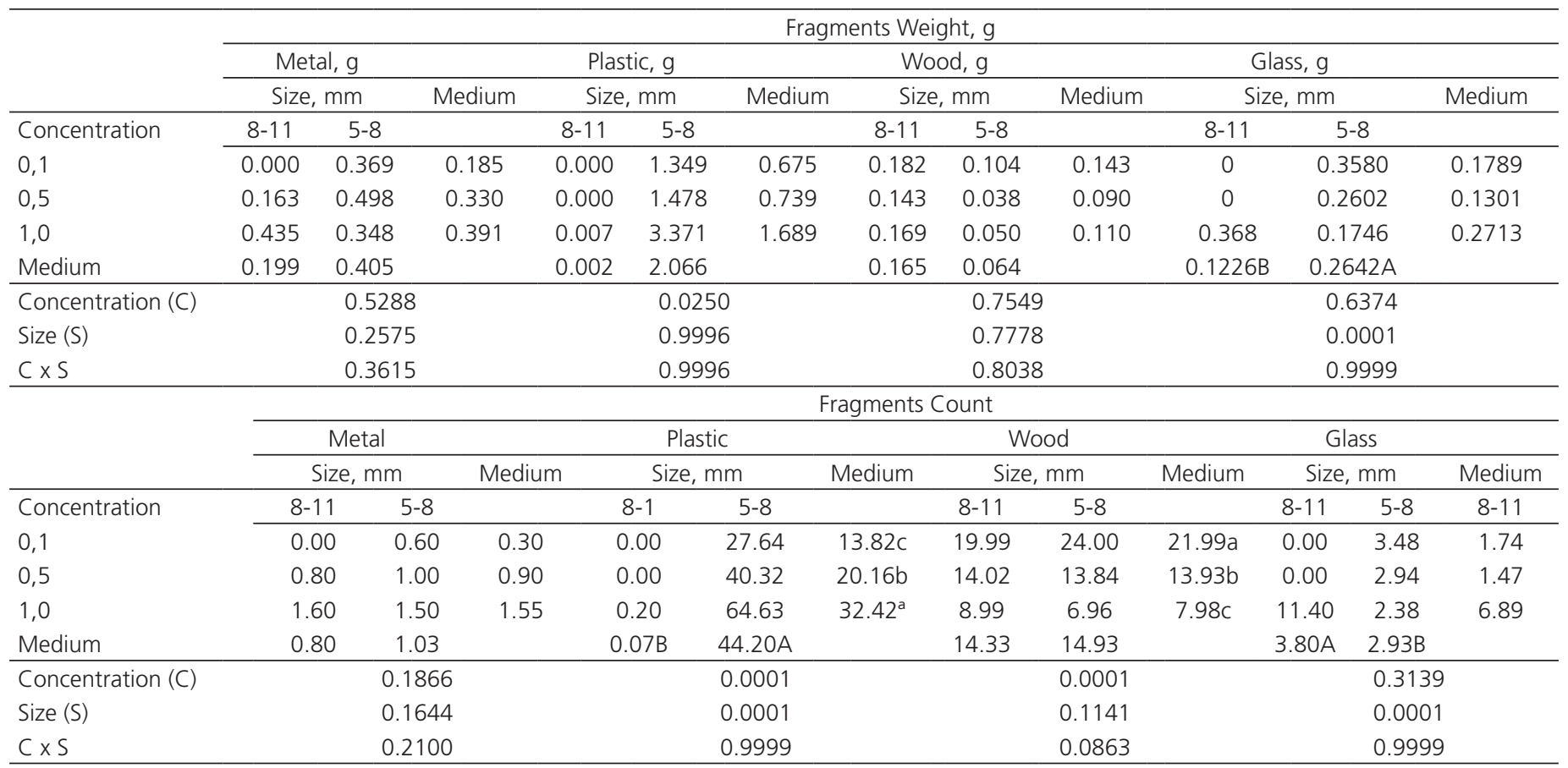

Lowercase letters in the column differ significantly and capital letters in the line differ significantly $(p<0.05)$.

smaller particles $(5-8 \mathrm{~mm})$. For the counting of plastic fragments, there was a higher ingestion $(p<0.05)$ of fragments of smaller size $(5-8 \mathrm{~mm})$, added to the poultry house litter in the highest concentration (1,0\%). For wood, consumption decreased as the concentration increased and for glass, the highest count $(p<0.05)$ was for the largest fragment size $(8-11 \mathrm{~mm})$.

The results according to the weight and count of the ingested fragments at 28 days are shown in Table 3. There was no significant interaction ( $p>0.05)$

Table 3 - Analysis of weight (grams) and number of fragments found in the gastrointestinal tract of birds at 28 days of age, unfolding the interaction Size $x$ Concentration.

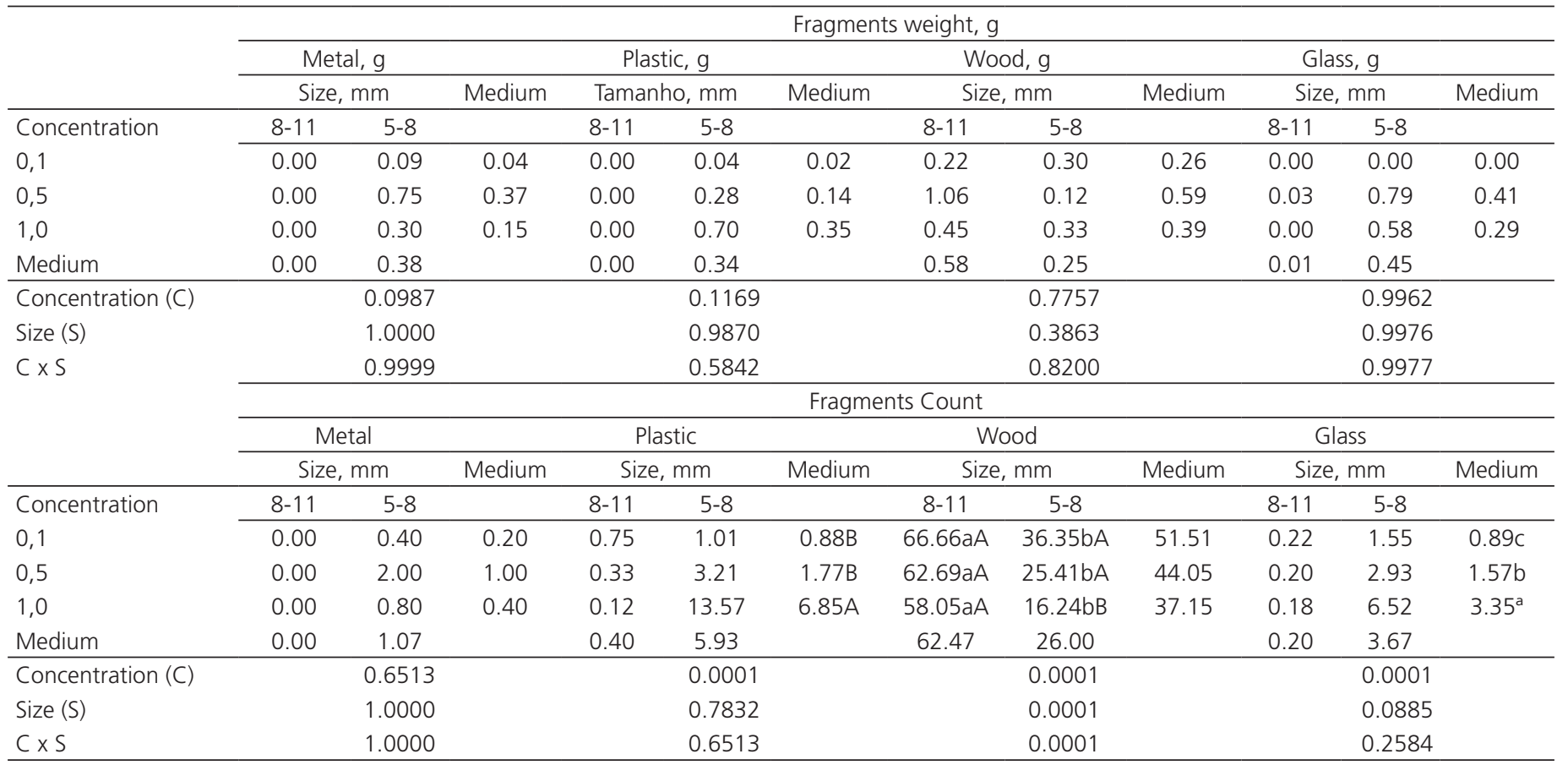

Lowercase letters in the column differ significantly and capital letters in the line differ significantly $(p<0.05)$. 
or isolated effect for size and concentration of the fragment's weight. For the counting there was a significant interaction $(p<0.05)$ for the wood, where it was observed a lower consumption $(p<0.05)$ for the smaller fragments $(5-8 \mathrm{~mm})$ in higher concentration $(1,0 \%)$. For the plastic, the count was higher only at the highest concentration $(1,0 \%)$ regardless of the size of the fragment and for the glass, a higher consumption was observed according to the increase in the concentration of fragments of both sizes.

At 35 days the weight of the fragments collected from the gastrointestinal tract of the birds did not show any effect $(p>0,05)$. The counting of plastic and wood particles had a significant effect for size, so that smaller fragments $(5-8 \mathrm{~mm})$ were consumed on a larger scale $(p<0,05)$. And for wood exclusively, there was a smaller consumption $(p<0,05)$ for higher concentrations $(0,5 \%-1,0 \%)$.

The ventricle or gizzard is the mechanical stomach, with an extremely thick keratin layer to protect the muscle, revested by the cuticle of koilin, protecting mucosa against the pressure of hard materials (Benjamin et al., 2015). This specialized stomach, made of thick muscular walls, is used to crush food, often like stone or gravel particles. Therefore, the gizzard has several important functions, such as reducing ingested particles size, chemical degradation of nutrients and regulation of food flow. The gizzard's efficacy for size and strength depends on the presence of stones, gravel, and sand (Svihus, 2011). Grains can be classified as soluble and insoluble. Soluble grain sources (limestone and oyster shell) are easily dissolved in gizzard, while sources of insoluble grains (silica, mica, and sand) are not digestible and are retained in gizzard (Adeniji \& Oyleke, 2008; Aruljothi et al., 2017).

Despite being considered foreign materials to the diet, in poultry farms, domestic or native birds ingest stones by scratching and pecking for food, aiding the gizzard's abrasive activity (Adeniji, 2009; Adeniji, 2010). Garipoglu et al. (2006) reported that voluntary consumption of stones by broilers increased intestinal length and empty gizzard weight, without affecting growth performance of broiler chickens. In a study that compared the behavior of wild and domesticated birds in man-controlled environments, results indicated that behavioral custom of birds in unconfined environments is generally preserved, with changes only in frequency and intensity of behavioral characteristics (Joseph et al., 1992). As this behavior remains, the presence of the fragments worked as an attractive to the environment of the aviary, therefore, this indicates that there is no environmental enrichment to the birds.

The low occurrence and even absence of severe lesions show that despite genetic evolution and confinement of birds, eliminating daily contact and consumption of small pebbles, plants and

Table 4 - Analysis of weight (grams) and number of fragments found in the gastrointestinal tract of birds at 35 days of age, unfolding the interaction Size $x$ Concentration.

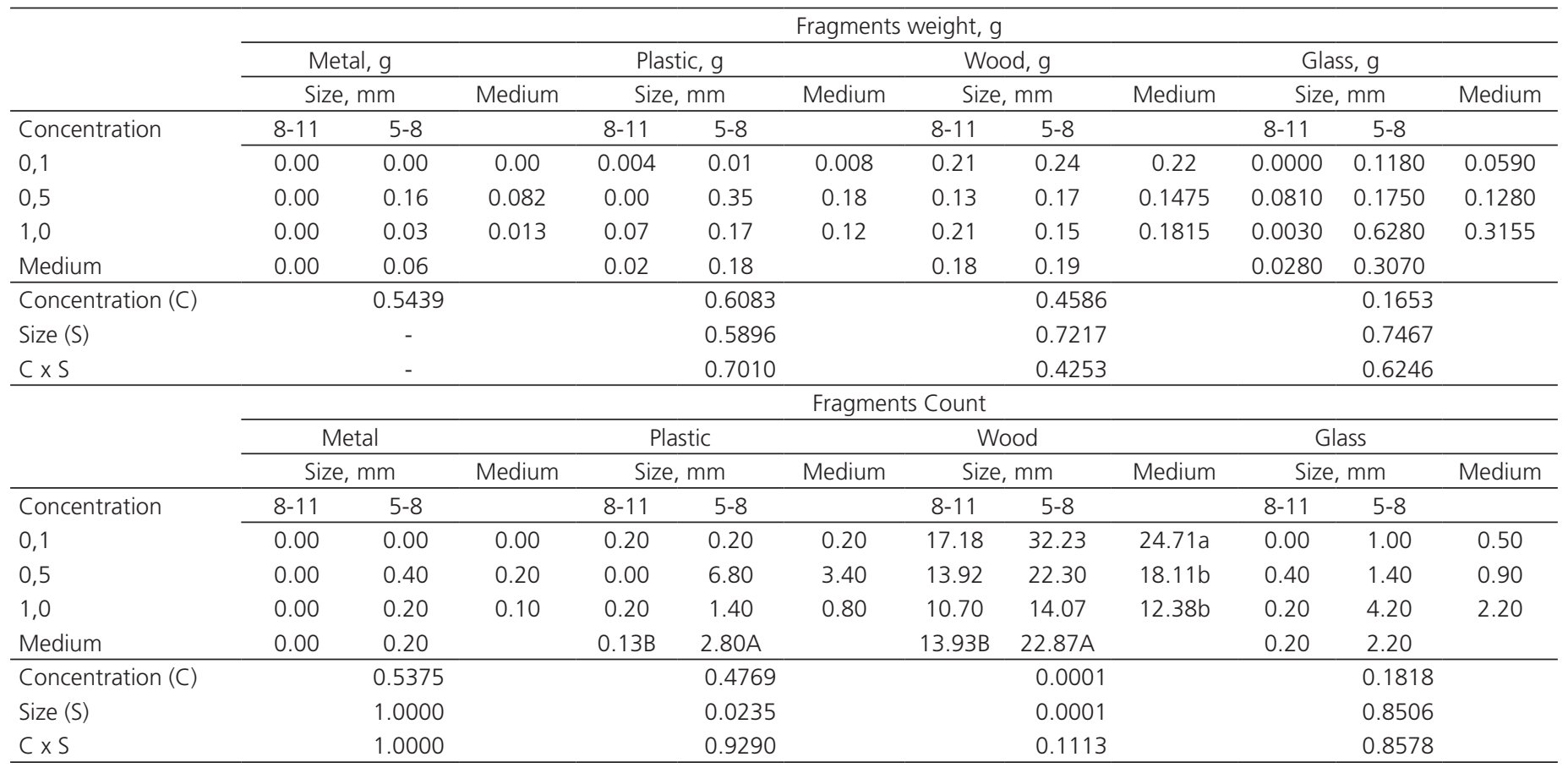

Lowercase letters in the column differ significantly and capital letters in the line differ significantly $(p<0.05)$. 
Fernandes JIM, Gonçalves DRM, Pazdiora DA, Santos AL, Oliveira MD, Marcante T, Guirro ECBP
Evaluation of the Ingestive Behavior of Foreign Fragments and the Integrity of Gastrointestinal Tract of Broiler Chickens materials of different textures and hardness, the birds maintain the ability to consume and eliminate these undigested materials without affecting the integrity of the gastrointestinal tract's mucosa. This finding corroborates Paranhos da Costa (2002), considering that even with environmental restrictions to which broiler chickens are submitted in confined facilities, birds can express typical behaviors of the species, since part of its behavioral expression is due to its biological structure. Foreign body ingestion occur mostly in perfectly healthy birds that are inquisitive and playful.

In this sense, the gizzard's grinding function in modern chicken has been maintained by the provision of coarsely ground diets, promoting the development and growth of the gizzard. The same effect is obtained by supplying pellet feeds composed of high hardness and good quality pellets.

Besides, Fernandes et al. (2013) demonstrate that broiler performance was not influenced by sorghum physical form (50\% ground or 50\% whole) and it was similar as those fed corn-based diets. The heavier gizzards and small intestines and the longer ceca recorded as a function of the presence of whole grains in the diet could be explained by the response of the gastrointestinal tract of broilers to the particle size of an ingredient that remains longer inside the gizzard, demonstrating an anatomic-physiological effort to maximize the digestive process.

On the other hand, reports of gastric lesions from foreign bodies are common in newborn birds kept in poultry house litter with crushed nutshells, ground corn cob, polystyrene packaging, cat sand and minced paper (Benjamin et al., 2015). Metallic and wood foreign bodies have been associated with proventricular dilation, whereas foreign metallic bodies may lead to ventricle perforation (Ingram, 1990). The ventricle is commonly affected due to its capacity of strong contractions. Gastric perforation can result in generalized acute peritonitis, local peritonitis with serous abscess formation, or acute fatal hemorrhage due to trauma to the hepatic vessels (Lumeij et al., 1994).

The clinical signs associated with the gastric foreign body are non-specific. Birds may present a medical history of intermittent lethargy, inappetence, recurrent bacterial enteritis, tenesmus, and vomiting. Some materials that constitute the foreign bodies, such as heavy metals, plastics, or rubbers, are potentially toxic and birds often show clinical symptoms of intoxication (Clipsham, 1992). It is also known that ulcerative lesions on the skin with formation of granulomas in broilers are associated with wood fragments or foreign bodies from the poultry house litter and have been observed in several carcasses in slaughterhouses (Fallavena, 2009).

The ingestion of foreign bodies from the poultry house litter that has been observed can be justified by Broom and Molento (2004), who describe that confined birds spend a lot of time in idleness, which intensifies behavior of "pecking and scratching", besides some behaviors like interacting with the new and different are remnants of their ancestors.

Attractive fragments, with vibrant colors and attractive texture for birds, such as plastic, metal, and glass particles, arouse interest in a monotonous environment. However, it was observed that smaller sized metal particles were less consumed. This may be due to the propensity of these small and heavy particles reaching the floor of the poultry house. Glass particles were poorly ingested as well, probably because they were unattractive or even unnoticed by birds.

Despite the great consumption of fragments, whether metal, glass, plastic or wood, the observed lesions were minimal. In macroscopic evaluation, some of these lesions probably are not related to the consumption of these fragments. The mucosal lesions observed may be the result of several nutritional situations (granulometry, peroxidase fat, excess fiber, presence of mycotoxins mainly of the $\mathrm{T} 2$ group, etc.) from management and pathogenic conditions, and then it is important to distinguish conditions that exhibits similar signs before reaching a definitive conclusion.

The stress of confinement together with access to foreign materials in the environment seems to play an important role in the dietary ingestion (Aruljothi et al., 2017). Thus, further researches should develop some alternatives of environmental enrichment for these animals to express their natural behavior. In fact, farm animal welfare is rated the single most important sustainability related food issue consumers have, above health or safety concerns. Information assists consumers in deriving satisfaction from food products and knowing the origin and environmental, ethical, and technological conditions under which these products are produced and processed (Asante-Addo \& Weible, 2020).

\section{CONCLUSIONS}

The fragment's occurrence in the poultry house litter of the same nature of the materials that were 
Fernandes JIM, Gonçalves DRM, Pazdiora DA, Santos AL, Oliveira MD, Marcante T, Guirro ECBP analyzed in this work in different sizes, colors and textures does not compromise the integrity of the mucosa of the gastrointestinal tract and the welfare of the birds. Even submitted to confined facilities, the birds are still capable to express typical behaviors of the species, since part of its behavioral expression is due to its biological structure. Therefore, the "pecking and pecking" behavior is inherent in the bird and does not compromise its sanity, welfare or the integrity of the mucosa of the gastrointestinal tract.

\section{REFERENCES}

Adeniji AA, Oyeleke MM. Effects of dietary grit fed on the utilization of rumen content by pullet chicks. Journal of Applied Sciences Research 2008;4:1257-1260.

Adeniji AA. Effects of dietary grit inclusion on the utilization of palm kernel cake by pullet chicks. Animal Nutrition and Feed Technology 2009;9:29-36.

Adeniji AA. Effects of dietary grit inclusion on the utilization of rice husk by pullet chicks. Tropical and Subtropical Agroecosystems 2010;12:175180.

Aruljothi A, Sivakumar K, Nithya P. Incidence of an unusual foreign body in the gizzard of a broiler chicken. International Journal of Science, Environment and Technology 2017;6(3):1852 - 1855.

Asante-Addo C, Weible D. Profiling consumers based on information use and trust in a developing economy. International Journal of Consumer Studies 2020;44(3):285-295.

Bilgili SF, Hess JB, Blake JP, Macklin KS, Saenmahayak B, Sibley JL. Influence of bedding material on foot pad dermatitis in broiler chickens. Journal Applied Poultry Research 2009;18:583-589.

Broom DM, Molento CFM. Bem-estar animal: conceitos e questões relacionadas - revisão. Archives of Veterinary Science 2004;9:1-11.

Clipsham R. Noninfectious diseases of pediatric psittacines. Seminars in Avian and Exotic Pet Medicine 1992;1(1):22-23.

Fallavena LCB. Fisiopatologia do sistema tegumentar. In: Berchieri Junior A, Silva EN, Di Fábio J, Sesti L, Zuanaze MAF, editors. Doenças das aves. Campinas: Fundação APINCO de Ciência e Tecnologia Avícolas; 2009. p.191-211.

Fiorentin, L. Reutilização da cama na criação de frangos de corte e as implicações de ordem bacteriológica na saúde humana e animal. Concórdia: Embrapa Suínos e Aves; 2005. 24p.

\section{Evaluation of the Ingestive Behavior of Foreign Fragments and the Integrity of Gastrointestinal Tract of Broiler Chickens}

Garipoglu AV, Erner G, Ocak N. Voluntary intake of insoluble granite-grit offered in free choice by broilers: its effect on their digestive tract traits and performances. Asian-Australasian Journal of Animal Science 2006;19(4):549-553.

Ingram IA. Proventricular foreign body mimicking proventricular dilatation in an umbrella cockatoo. Proceedings of the Annual Conference of the Association of Avian Veterinarians; 1990; Phoenix, Arizona. USA. 1990. p.314-315.

Joseph MM. Applications of behavior to poultry management. Poultry Science 1992;71:634-642.

Lumeij JT. Gastroenterology. In: Richie BW, Harrison GJ, Harrison LR, editors. Avian medicine: principles and application. Lake Worth: Wingers Publishing; 1994. p.482-521.

Nääs IA, Mollo Neto M, Canuto SA, Waker R, Oliveira DRMS, Vendrametto O. Brazilian chicken meat production chain: a 10-year overview. Brazilian Journal of Poultry Science 2015;17(1):87-94.

Napolitano F, Girolami A, Braghieri A. Consumer liking and willingness to pay for high welfare animal-based products. Trends in Food Science and Technology 2010;21:537-543.

Oliveira CB, Bortolli EC, Barcellos JOJ. Diferenciação por qualidade da carne a ótica do bem-estar animal. Ciência Rural 2008;38:2092-2096.

Olsen AR, John S, Gecan JS, Ziobro GC, Bryce JR. Regulatory action criteria for filth and other extraneous materials. V. Strategy for evaluating hazardous and nonhazardous filth. Regulatory Toxicology and Pharmacology 2001;33:363-392.

Olsen AR. Regulatory action criteria for filth and other extraneous materials. II. Allergenic mites: an emerging food safety issue. Regulatory Toxicology and Pharmacology 1998;28(3):190-198.

Paranhos da Costa MJR. Comportamento e bem-estar. In: Macari M, Furlan RL, Gonzales E. Fisiologia aviária aplicada a frangos de corte. Jaboticabal: FUNEP/UNESP; 2002. p.327-345.

Pilecco M, Paz ICLA, Tabaldi LA, Francisco LA, Caldara FR, Garcia RG. Treinamentos de boas práticas de fabricação de rações:qual a freqüência ideal? Agrarian 2012;5(17):295-302.

Svihus B. The gizzard: function, influence of diet structure and effects on nutrient availability. World's Poultry Science Journal 2011;67(2):207224.

Waker R, Nääs, I. Structural attributes dynamics of the brazilian broiler production chain. Brazilian Journal of Poultry Science 2018;20(3):517526. 